\title{
An EIS study of DNA-modified electrodes
}

\author{
Christopher M.A. Brett ${ }^{\mathrm{a}, *}$, Ana Maria Oliveira Brett ${ }^{\mathrm{a}, 1}$, Silvia H.P. Serrano ${ }^{\mathrm{b}}$ \\ ${ }^{a}$ Departamento de Química, Universidade de Coimbra, 3049, Coimbra, Portugal \\ ${ }^{\mathrm{b}}$ Instituto de Química, Universidade de São Paulo, CP 26077, 05599-970, São Paulo, Brazil
}

Received 7 August 1998; received in revised form 28 January 1999

\begin{abstract}
The preparation and conditioning of DNA-modified electrodes, in which glassy carbon electrodes are covered by a thick film of double-stranded DNA and subsequently conditioned in acetate buffer, has been followed with Electrochemical Impedance Spectroscopy. Spectra were recorded at different values of applied potential in order to probe the alterations occurring in the modifier layer. The alterations in the EIS response parallel the changes in voltammetric response and show that the modifier layer is a good conductor and that the behaviour as a DNAbiosensor is essentially due to surface phenomena and interaction with single-stranded DNA in solution during conditioning. (C) 1999 Elsevier Science Ltd. All rights reserved.
\end{abstract}

Keywords: DNA-modified electrodes; Electrochemical impedance; Guanine; Adenine; Double-stranded DNA; Single-stranded DNA

\section{Introduction}

The electrochemical reduction behaviour of DNA and its adsorption at mercury electrodes have been well known since the beginning of the 1960s [1]. Differential pulse voltammograms show a well-defined peak due to the simultaneous reduction of adenine and cytosine residues in the DNA molecule; the intensity of the current peak as well as the peak potential are dependent on the structural state of DNA in the solution. Guanine produces an anodic peak on the reverse scan in cyclic voltammetry, due to the oxidation of guanine reduction products formed at a potential close to hydrogen evolution [1].

The electrochemical oxidation of DNA was studied with carbon electrodes [2-4]; anodic peaks are due to the oxidation of guanine, adenine, thymine and cytosine residues [5]. Higher current peaks observed in

\footnotetext{
* Corresponding author. Fax: +351-39-835295

${ }^{1}$ Corresponding co-author
}

ssDNA (single strand DNA) in comparison with dsDNA (double strand DNA) were attributed to greater ease of ssDNA adsorption on the electrode surface [34]. Nucleic acids and their bases are reduced or oxidised at electrodes from the adsorbed state [6-10] and sensitive determinations $(<1 \mu \mathrm{M})$ by using adsorptive transfer stripping voltammetry [11-15] or potentiometric stripping at carbon paste electrodes [16-17] were described.

Detailed studies have been undertaken on the adsorption of DNA treated with perchloric acid on glassy carbon electrode surfaces [18]. Higher current peaks were observed for the oxidation of guanine and adenine compared with previously published results [19]. This difference cannot be explained taking into account only the DNA apurination effect [20], since no poisoning of the electrode surface occurred, contrary to what was observed for the oxidation of free adenine [21] or 2'-deoxyadenosine-5'-monophosphate [22]. Modification of glassy carbon surfaces by immobilisation of dsDNA has also been described [23]. After drying, these sensors were held at $1.4 \mathrm{~V}$ in $\mathrm{pH} 4.5$ acet- 
ate buffer for 5 min and were then subjected to a conditioning procedure in acetate buffer solution containing DNA, previously treated with perchloric acid, after which they respond to species in solution that are sensitive to interaction with DNA, such as drugs [24-26] and cytostatic agents [23]. This DNA biosensor therefore provides a unique probe for the interaction of substances with DNA, the timescale of the interaction and the way in which it occurs.

The purpose of this study was to use EIS, in conjunction with results from voltammetric techniques, to help understand what is occurring during the preparation and conditioning procedure of the DNA-biosensor in acetate buffer solution containing DNA. This whole procedure is absolutely essential for the useful functioning of the sensor, and must involve some form of structural rearrangement at the level of molecular DNA on the sensor layer surface, as will be seen below.

\section{Experimental}

DNA-modified glassy carbon electrodes were prepared by covering a polished glassy carbon disc electrode, diameter $3 \mathrm{~mm}$, with $3 \mathrm{mg}$ of dsDNA dissolved in $80 \mu \mathrm{l}$ of $\mathrm{pH} 4.50 .2 \mathrm{M}$ acetate buffer and leaving the electrode to dry overnight. This led to an almost uniform layer of DNA $\sim 0.1 \mathrm{~mm}$ thick when dry, which in aqueous solution swells to about $1 \mathrm{~mm}$ thickness with a gel-like appearance. ssDNA was prepared by treating a sample of $3 \mathrm{mg}$ calf thymus dsDNA with $0.5 \mathrm{ml}$ of $60 \%$ pure perchloric acid; immediately following dissolution, $0.5 \mathrm{ml}$ of $9 \mathrm{M} \mathrm{NaOH}$ were added to neutralize the solution and then $9 \mathrm{ml}$ of $\mathrm{pH} 4.5$ acetate buffer.

Conditioning experiments were carried out in a onecompartment cell containing the DNA-modified electrode, a Pt wire auxiliary electrode and a saturated calomel electrode (SCE) as reference, with an EcoChemie $\mu$ Autolab potentiostat controlled by GPES3 software. Initially, the as-prepared DNA-modified electrode was held at $1.4 \mathrm{~V}$ vs SCE in $\mathrm{pH} 4.5$ acetate buffer solution for $5 \mathrm{~min}$.

The conditioning procedure was carried out in acetate buffer solution containing ssDNA by scanning the applied potential using differential pulse voltammetric scans from $0.0-1.4 \mathrm{~V}$ vs SCE at $5 \mathrm{mV} \mathrm{s}^{-1}$; pulse width was $50 \mathrm{~ms}$ and pulse height, $50 \mathrm{mV}$. Between scans the electrode was held at $0.0 \mathrm{~V}$ or $1.4 \mathrm{~V}$ for $2 \mathrm{~min}$ with constant stirring. Scans were repeated until no difference between successive recordings was noticed, i.e. when the peaks corresponding to oxidation of guanine and adenine residues (at 0.75 and $1.10 \mathrm{~V}$, respectively) did not increase further. The electrode was then placed in buffer solution for $2 \mathrm{~min}$, removed and left to dry for $4 \mathrm{~h}$.

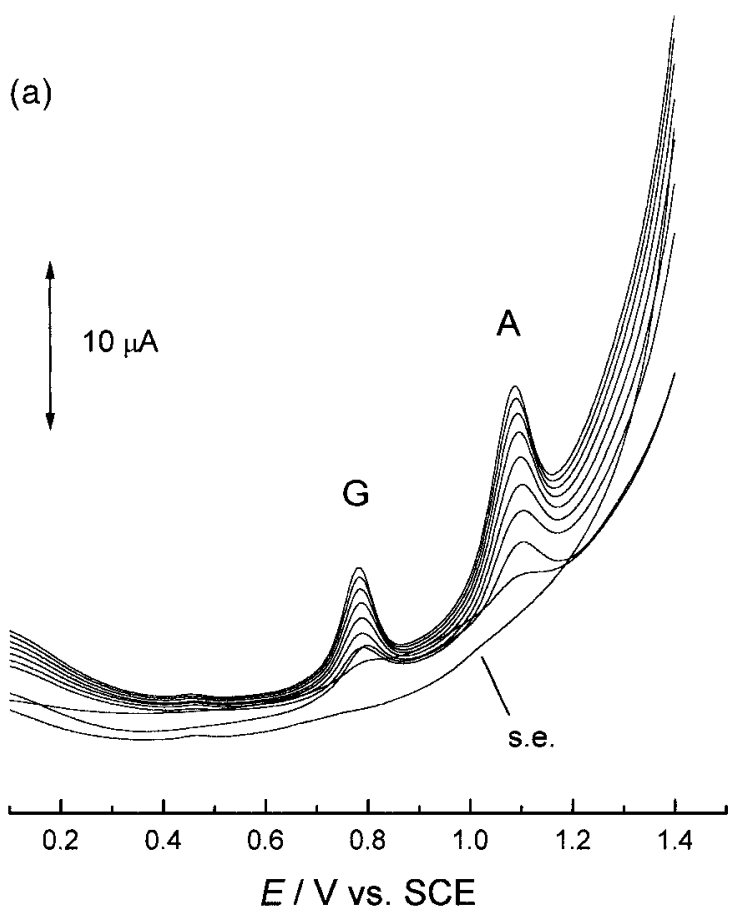

(b)

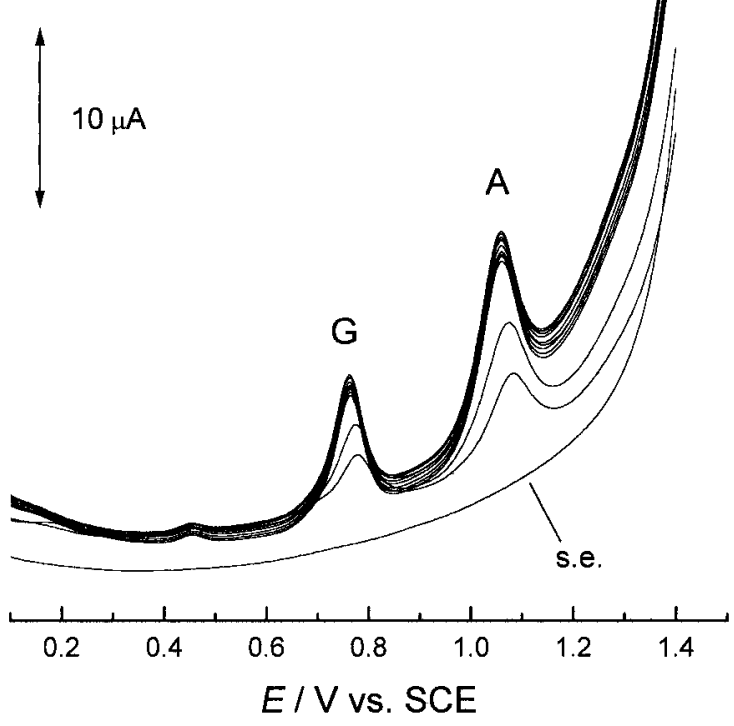

Fig. 1. Differential pulse (DP) voltammograms for the DNA modified electrode over the 1st conditioning cycle in DNAcontaining acetate buffer solution; potential between scans held at (a) $0.0 \mathrm{~V}$ (b) $1.4 \mathrm{~V}$. G = guanine, $\mathrm{A}=$ adenine. 

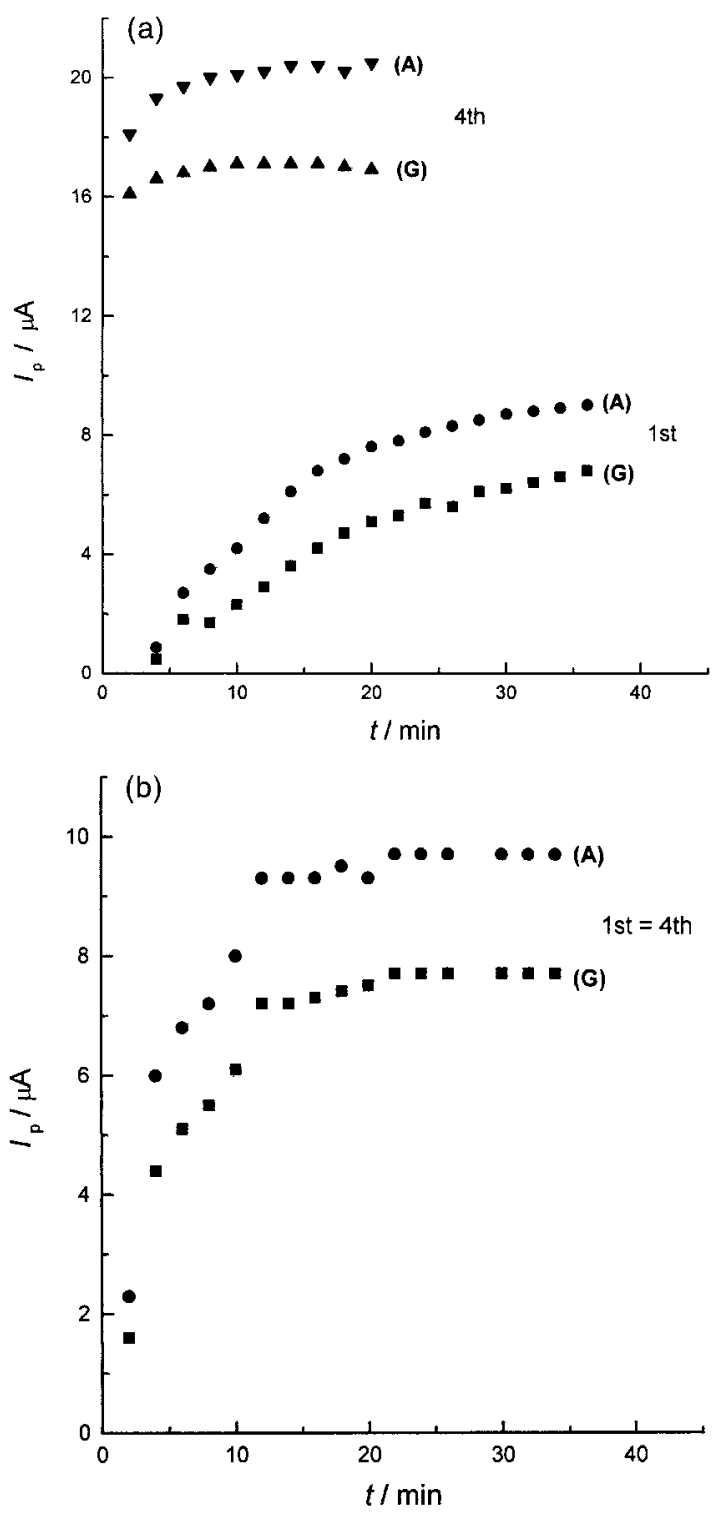

Fig. 2. Plots of DP current peaks (from voltammograms of type shown in Fig. 1) over 1st and 4th conditioning cycles after holding electrode between scans at (a) $0.0 \mathrm{~V}$ and (b) $1.4 \mathrm{~V} . \mathrm{G}=$ guanine, $\mathrm{A}=$ adenine.

The full conditioning procedure described above was repeated at least four times.

Impedance data were recorded at different applied potentials during the conditioning procedure, corresponding to before the guanine oxidation peak $(0.3 \mathrm{~V})$, between guanine and adenine oxidation peaks $(1.0 \mathrm{~V})$ and after adenine oxidation $(1.4 \mathrm{~V})$. A Solartron 1250 Frequency Response Analyser coupled to a Solartron 1286 Electrochemical Interface was used with ZPlot (Scribner Associates) control software. An rms pertur- bation of $10 \mathrm{mV}$ was applied and logarithmic frequency scans, 5 frequencies per decade, were performed over the frequency range $65 \mathrm{kHz}$ to $0.1 \mathrm{~Hz}$. Fitting of impedance spectra was done using ZSim/ CNLS impedance simulation and modelling software Version 4.1 (Scribner Associates).

\section{Results and discussion}

\subsection{Voltammetric experiments}

The effect of the conditioning procedure on the voltammetry of the DNA-modified electrode is illustrated in Figs. 1 and 2. Fig. 1 shows differential pulse scans in the positive direction for the first conditioning cycle; two current peaks are evident-for oxidation of guanine $(\sim 0.8 \mathrm{~V}$ vs SCE$)$ and of adenine $(\sim 1.1 \mathrm{~V}$ vs SCE$)$ residues. Fig. 1a shows voltammograms after holding the potential at $0.0 \mathrm{~V}$ before the scans and Fig. $1 \mathrm{~b}$, after holding at $1.4 \mathrm{~V}$. Several deductions from such data can be made:

1. Over each cycle the peak currents increase, tending towards a limiting value. Once this limiting value is reached, the conditioning cycle is deemed to be finished.

2. The range of currents becomes higher in successive conditioning cycles, reaching a maximum after 4 or 5 cycles when $0 \mathrm{~V}$ is applied during the 2-min period between scans, but effectively reaching the maximum after one conditioning cycle with $1.4 \mathrm{~V}$ applied potential between scans. This is illustrated in Fig. 2. It also shows that higher final currents are achieved if the potential applied between scans is $0.0 \mathrm{~V}$.

3. Background currents increase slightly during the full conditioning procedure. This can be indicative of various processes, but it should be recalled that (in principle) the current sampling in differential pulse voltammetry will have a capacitive component if the sampling towards the end of the pulse is carried out too early. This increased background current could be indicative, therefore, of an increased time constant.

Thus, it was decided to make impedance measurements at various stages during the preparation of the DNA biosensor at applied potentials of $0.3,1.0$ and $1.4 \mathrm{~V}$, corresponding to before the potential for oxidation of guanine, between guanine and adenine, and after the potential for oxidation of adenine.

\subsection{Electrochemical impedance}

Impedance experiments were carried out at various stages during the conditioning procedure. Spectra 

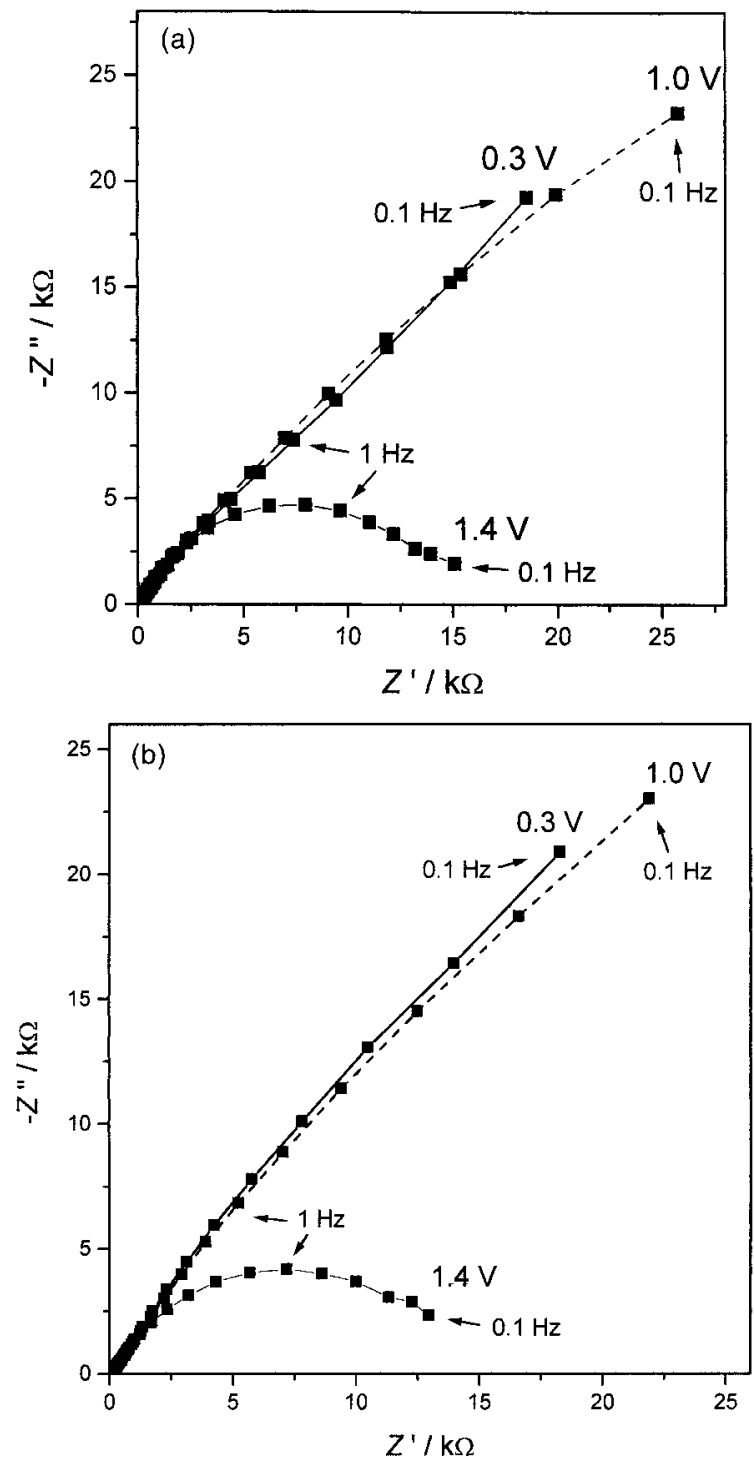

Fig. 3. Complex plane impedance spectra at $0.3,1.0$ and $1.4 \mathrm{~V}$ for a DNA-modified electrode in acetate buffer solution (a) before and (b) after application of $1.4 \mathrm{~V}$ for $5 \mathrm{~min}$.

recorded in acetate buffer solution at a freshly-prepared electrode, before any potential was applied, are shown in Fig. 3a, and $3 \mathrm{~b}$ shows the corresponding spectra after $1.4 \mathrm{~V}$ had been applied for $5 \mathrm{~min}$. As can be seen, there is no significant difference between the spectra. At applied potentials of 0.3 and $1.0 \mathrm{~V}$, there are strong indications of diffusional characteristics, and at $1.4 \mathrm{~V}$ the smaller semi-circle is due to a small amount of oxygen evolution. These results correlate with the fact that differential pulse voltammograms still show no peaks for oxidation of guanine and adenine residues after this initial treatment. In any case,
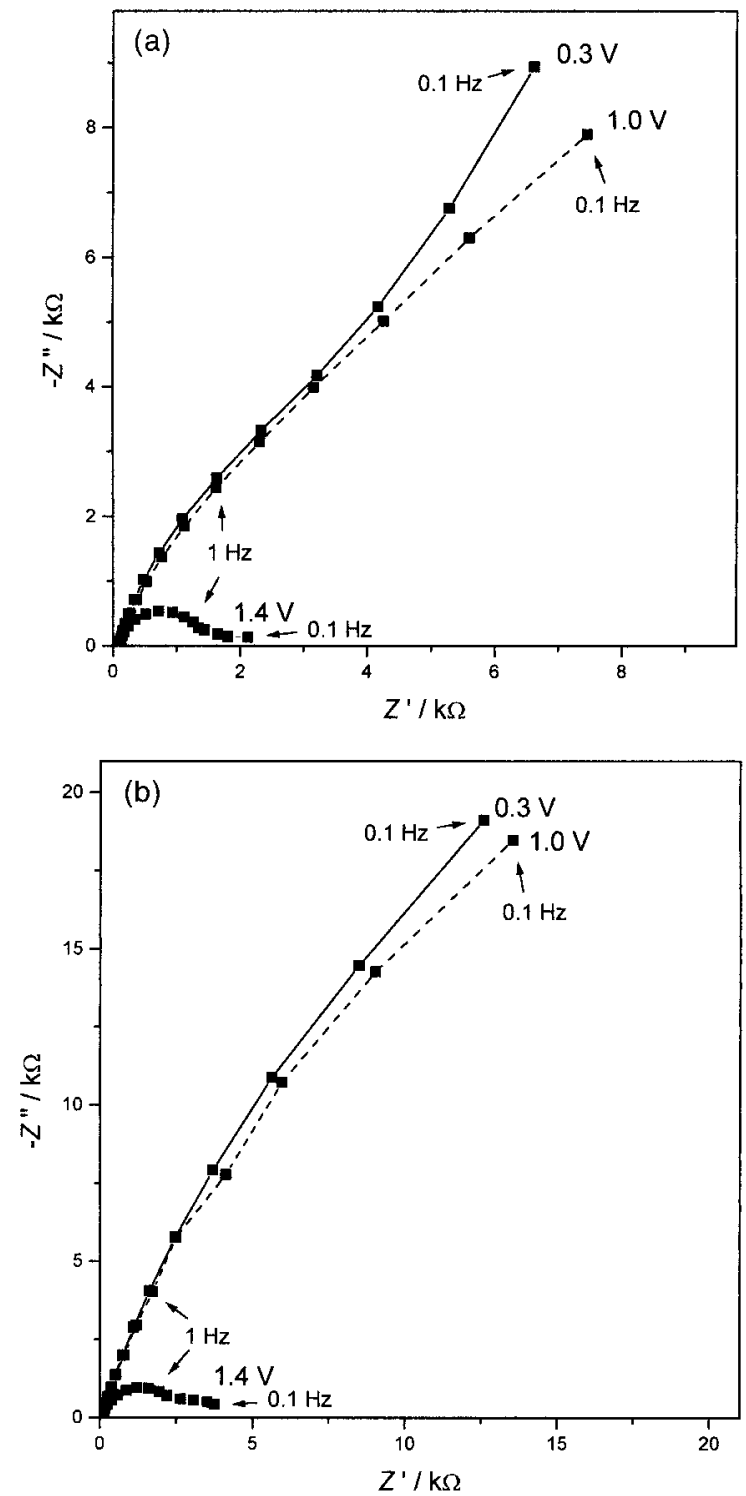

Fig. 4. Complex plane impedance spectra at $0.3,1.0$ and $1.4 \mathrm{~V}$ for a DNA-modified electrode after the conditioning procedure at $0.0 \mathrm{~V}$ in $\mathrm{pH} 4.5$ acetate buffer containing ssDNA after (a) 1st conditioning cycle; (b) 4th conditioning cycle.

the small intercept on the real axis of $80-100 \Omega$ shows that the bulk modifier film (up to $1.0 \mathrm{~mm}$ thick when hydrated) is a reasonably good conductor; other experiments with bare glassy carbon electrodes gave the same value.

The electrode was then placed in DNA-containing acetate buffer solutions. Figs. 4 and 5 show impedance spectra after the 1st and last conditioning cycles using applied potentials of 0.0 and $1.4 \mathrm{~V}$ between cycles, respectively. Evidence of a pseudo-capacitance at $0.3 \mathrm{~V}$ 

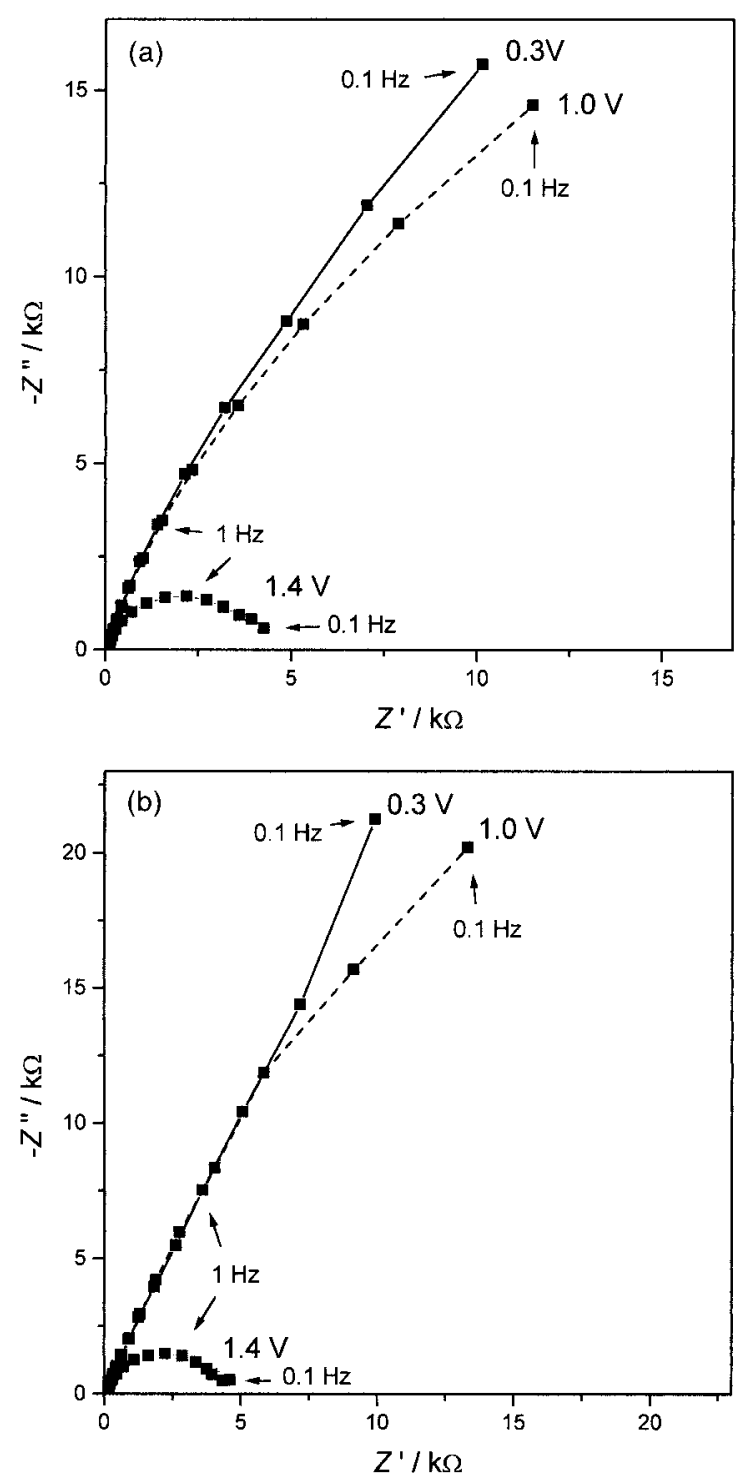

Fig. 5. Complex plane impedance spectra at $0.3,1.0$ and $1.4 \mathrm{~V}$ for a DNA-modified electrode after the conditioning procedure at $1.4 \mathrm{~V}$ in $\mathrm{pH} 4.5$ acetate buffer containing ssDNA after (a) 1st conditioning cycle; (b) 5th conditioning cycle.

in Fig. 4a after the first modification cycle disappears by the 4 th cycle. Additionally, the impedance values at 0.3 and $1.0 \mathrm{~V}$ applied potential, increase by a factor of approximately two.

If the applied potential between scan cycles is held at $1.4 \mathrm{~V}$, then the impedance values are higher initially and vary less - however, the final values are similar to those obtained in the conditioning procedure with applied potential $0.0 \mathrm{~V}$. No evidence of a pseudo-capacitance is seen at any stage.

\subsection{Comparison of impedance results}

It was attempted to model the impedance spectra by an equivalent circuit which makes physical sense and is appropriate for analysing all the spectra obtained at different stages in the conditioning procedure. Particular attention was given to the results obtained at 0.3 and $1.0 \mathrm{~V}$ applied potential, which correspond to zones in which there is no faradaic reaction. Apart from the ohmic resistance, modelling used two capacitances in parallel, $C_{1}$ and $C_{2}$, the second, $C_{2}$, with constant phase angle characteristics ( $\alpha$ always found to be between 0.5 and 0.6 ). In fact, there is visually evident roughness and porosity. These can be associated with the capacitance of two types of DNA-solution interfacial region: the major part, subject to restructuring but not interaction with ssDNA (see below) $\left(C_{1}\right)$ and the other part where interaction with ssDNA in solution takes place $\left(C_{2}\right)$, which in principle should lead to greater charge separation. Fitting of the equivalent circuit was very good in Bode plots except for errors in the phase angle at high frequency, but could be optimised further by inclusion of additional elements; however, it was felt to be preferable to use this rather than a more complicated circuit. However, the equivalent circuit for the spectra at $0.3 \mathrm{~V}$ after the first conditioning cycle at $0.0 \mathrm{~V}$, showed larger errors, as can be predicted from inspection of Fig. 4. Values of $C_{1}$ and $C_{2}$ are given in Table 1 .

General deductions which can be made from the spectra obtained are:

- the ohmic resistance of the system is hardly increased by the presence of the modifier layer (comparison with bare glassy carbon substrate), showing that the substrate surface is covered by a good electron conductor; there is more evidence of this in other electrochemical experiments [22]

- the interfacial capacity is similar at 0.3 and $1.0 \mathrm{~V}$, but decreases significantly at $+1.4 \mathrm{~V}$ when a semicircle appears together with a charge transfer resistance (probably solvent decomposition). Table 1 shows estimated values for the interfacial capacitance;

- as the number of scans increases, especially during the first conditioning cycle, the interfacial capacity, $\mathrm{C}_{2}$, also increases, suggesting adsorption of a component from solution, maybe together with some rearrangement of the molecules at the surface and close to the surface. Later on the values decrease to the initial values. However, $C_{1}$ is increased by an order of magnitude from the values when the DNAmodified electrode is prepared. This suggests that any alteration to the electrode penetrates to the right within the modifier layer. 
An explanation of the observed phenomena based on the general aspect of the impedance spectra and the quantitative evaluation referred to above is as follows. First, it must be recalled that without ssDNA in solution, no voltammetric oxidation response is obtained; therefore ssDNA takes part in the conditioning process. Indeed, the large impedance values observed in buffer solution (Fig. 3) as compared with those obtained after conditioning in DNA solution reflect structural modification of DNA on the electrode surface. Thus, the applied potential serves to alter the conformation of the dsDNA, opening up sites near the surface where ssDNA can be absorbed, and the residues which lead to the voltammetric response are from ssDNA.

Sodium ions from the supporting electrolyte, introduced into the modifier layer during electrode preparation, are removed from their DNA complexation sites (phosphate groups, nitrogen in the bases and hydroxyl of sugars) by exchange with ssDNA from solution, which interacts with dsDNA to produce a more energetically favourable structure. This process is easier and seems to be more effective at an applied potential of $1.4 \mathrm{~V}$ rather than $0.0 \mathrm{~V}$, as the more positive potential will aid the expulsion of $\mathrm{Na}^{+}$to a greater extent. In fact, the pseudo-capacitance observed in Fig. $4 \mathrm{a}$ at $0.3 \mathrm{~V}$ gives evidence of charge separation at the surface during the initial stages of ssDNA adsorption.

Over several conditioning cycles, there is a levelling off of the current in the successive scans in each conditioning cycle. This suggests that ssDNA penetrates further into the modifier layer until diffusion becomes limiting; the impedance spectra give further evidence for this. Rehydration following the drying period between conditioning cycles allows the structure to adapt better to the changes imposed externally, making further incorporation of ssDNA possible.

It is important to remember that DNA is a structurally polymorphic macromolecule which, depending on nucleotide sequence and environmental conditions, can adopt a variety of conformations. The double helical structure of DNA consists of two strands, each of them on the outside of the double helix and formed by alternating phosphate and pentose groups in which phosphodiester bridges provide the covalent continuity. In this B-DNA, the two chains of the double helix are held together by hydrogen bonds between purine and pyrimidine bases. It was discovered that when DNA is strongly dehydrated, a structural alteration occurs due to a greater electrostatic interaction between the phosphate groups, leading to A-DNA.

The different structural forms of the double helix have different dynamic interactions, and the width of the grooves between the strands is important in allowing or preventing access to bases. When the electrode con- 
taining dsDNA immobilized on the surface is immersed in a solution containing ssDNA and a potential of 0 or $+1.4 \mathrm{~V}$ is applied, migration of ssDNA will occur and interaction between dsDNA and ssDNA, leading to modification of the DNA conformation.

It is probable that the interaction of ssDNA from bulk solution with surface-bound dsDNA forms portions of triple helix DNA on the electrode surface [2729]. Triple-stranded DNA can be generated intermolecularly or intramolecularly. It is called H-DNA in order to indicate the high $\mathrm{H}^{+}$concentration of the media where this triplex exists and can only be formed if one strand of the original B-helix is all purine bases, guanine and adenine, and the corresponding region of the other strand is all pyrimidine bases, thymine and cytosine.

Triple-stranded DNA has been monitored electrochemically by hydroxylamine (which is a specific chemical probe for triple-stranded DNA [30]) formed during the electrochemical reduction of nitroimidazoles [26]. The electrochemical characteristics of these DNAbiosensors have been evaluated [22].

From the impedance spectra obtained it is not easy to obtain exact quantitative data on the conditioning process, as mentioned above. The system is complex, as are the changes occurring. However, the spectra provide more direct evidence of the occurrence of surface phenomena during the procedure than can be demonstrated by voltammetric techniques.

\section{Conclusion}

Electrochemical impedance spectroscopy has been employed to characterise the changes occurring during the preparation and conditioning of a DNA-modified electrode. An explanation based on changes in the conformation of dsDNA through its interaction with ssDNA from solution to produce a modifier layer with triple helix DNA, is supported by the impedance and the voltammetric experimental results.

\section{Acknowledgements}

S.H.P.S. thanks FAPESP, Brazil, for financial support.

\section{References}

[1] E. Palecek, Electroanalysis 8 (1996) 7.
[2] T. Yao, T. Wasa, S. Musha, Bull. Chem. Soc. Jpn. 51 (1978) 1235.

[3] V. Brabec, G. Dryhurst, J. Electroanal. Chem. 89 (1978) 161.

[4] E. Palecek, in: G. Milazzo (Ed.), Topics in Bioelectrochemistry and Bioenergetics, vol. 5, Wiley, London, 1983, p. 65.

[5] A.M. Oliveira Brett, F-M. Matysik, J. Electroanal. Chem. 429 (1997) 95.

[6] P. Valenta, P. Grahmann, J. Electroanal. Chem. 49 (1976) 55.

[7] P. Valenta, H.W. Nuernberg, P. Klahre, Bioelectrochem. Bioenerg. 1 (1974) 487.

[8] P. Valenta, H.W. Nuernberg, P. Klahre, Bioelectrochem. Bioenerg. 2 (1975) 204.

[9] H. Berg, J. Flemming, G. Horn, Bioelectrochem. Bioenerg. 2 (1975) 287.

[10] J.A. Reynaud, Bioelectrochem. Bioenerg. 7 (1980) 267.

[11] E. Palecek, I. Postbieglová, J. Electroanal. Chem. 214 (1986) 359.

[12] E. Palecek, Bioelectrochem. Bioenerg. 20 (1988) 171.

[13] E. Palecek, Anal. Biochem. 170 (1988) 421.

[14] E. Palecek, M. Fojta, Anal. Chem. 66 (1994) 1566.

[15] M. Fojta, C. Teijeiro, E. Palecek, Bioelectrochem. Bioenerg. 34 (1994) 69.

[16] J. Wang, X. Cai, J. Wang, C. Jonsson, E. Palecek, Anal. Chem. 67 (1995) 4065.

[17] J. Wang, X. Cai, E.C. Jonsson, M. Balakrishnan, Electroanalysis 8 (1996) 20.

[18] C.M.A. Brett, A.M. Oliveira Brett, S.H.P. Serrano, J. Electroanal. Chem. 366 (1994) 225.

[19] E. Palecek, E. Jelen, C. Teijeiro, V. Fucik, T.M. Jovin, Anal. Chim. Acta 273 (1973) 175.

[20] F. Jelen, M. Fojta, E. Palecek, J. Electroanal. Chem. 427 (1997) 49

[21] G. Dryhurst, P.J. Elving, J. Electrochem. Soc. 115 (1968) 1014.

[22] A.M. Oliveira Brett, S.H.P. Serrano, J.A.P. Piedade, in: R.G. Crompton, G. Hancock (Eds.). Comprehensive Chemical Kinetics, Vol. 37, Elsevier, Amsterdam, 1999, Chapter 3.

[23] A.M. Oliveira Brett, S.H.P. Serrano, T.A. Macedo, D. Raimundo, M.H. Marques, M.A. La-Scalea, Electroanalysis 8 (1996) 992.

[24] A.M. Oliveira Brett, S.H.P. Serrano, I. Gutz, M.A. LaScalea, Bioelectrochem. Bioenerg. 42 (1997) 175.

[25] A.M. Oliveira Brett, S.H.P. Serrano, I. Gutz, M.A. LaScalea, Electroanalysis 9 (1997) 110.

[26] A.M. Oliveira Brett, S.H.P. Serrano, I. Gutz, M.A. LaScalea, M.L. Cruz, Electroanalysis 9 (1997) 1132.

[27] C. Shin, H-S. Koo, Biochemistry 35 (1996) 968.

[28] V.N. Potaman, R.R. Sinden, Biochemistry 34 (1995) 14,885 .

[29] V.N. Soyfer, V.N. Potaman, Triple-Helical Nucleic Acids, Springer, New York, 1995.

[30] B.H. Johnston, in: D.M.J. Lilley, J.E. Dahlberg (Eds.), Methods in Enzymology, vol. 212, Academic Press, San Diego, 1992, p. 180 Chapter 10. 